1992-01-01

\title{
Characterization of As-Prepared and Annealed W/C Multilayer Thin Films
}

David D. Allred

allred@byu.edu

Qi Wang

Jesus González-Hernández

B. S. Chao

D. A. Pawlik

Follow this and additional works at: https://scholarsarchive.byu.edu/facpub

Part of the Astrophysics and Astronomy Commons, and the Physics Commons

\section{Original Publication Citation}

The following article appeared in J. González-Hernández, B.S. Chao, D.A. Pawlik, D.D. Allred, and Qi Wang, "Characterization of as-prepared and annealed W/C multilayer thin films," Journal of Vacuum Science Technology 1(1), 145151 (1992). and may be found at [http://avspublications.org/jvsta/resource/1/jvtad6/v1/i1/p145_s1][http://dx.doi.org/1.1116/ 1.578127].

\section{BYU ScholarsArchive Citation}

Allred, David D.; Wang, Qi; González-Hernández, Jesus; Chao, B. S.; and Pawlik, D. A., "Characterization of As-Prepared and Annealed W/C Multilayer Thin Films" (1992). Faculty Publications. 718.

https://scholarsarchive.byu.edu/facpub/718

This Peer-Reviewed Article is brought to you for free and open access by BYU ScholarsArchive. It has been accepted for inclusion in Faculty Publications by an authorized administrator of BYU ScholarsArchive. For more information, please contact ellen_amatangelo@byu.edu. 


\title{
Characterization of as-prepared and annealed W/C multilayer thin films
}

\author{
J. Gonzalez-Hernandez, ${ }^{\text {a) }}$ B.S. Chao, and D.A. Pawlik \\ Energy Conversion Devices, Inc., Troy, Michigan 48084 \\ D. D. Allred and Qi Wang \\ Department of Physics, Brigham Young University, Provo, Utah 84602
}

(Received 16 May 1991; accepted 7 September 1991)

\begin{abstract}
Tungsten/carbon (W/C) multilayer thin films were prepared by dc magnetron sputtering. All samples consisted of 30 layer pairs with a nominal $d$ spacing varying from 2.5 to $14 \mathrm{~nm}$, the W layer thickness was kept at $2 \mathrm{~nm}$ in all samples. The $\mathrm{W} / \mathrm{C}$ multilayers were subjected to isochronal anneals in a quartz tube furnace at the temperature range from 500 to $950^{\circ} \mathrm{C}$ under a flow of high purity Ar gas. X-ray diffraction, Raman scattering, and Auger depth profile were used to characterize the structure of the as-prepared and annealed multilayer films. Both the $\mathrm{W}$ and $\mathrm{C}$ layers appear to be amorphous as-prepared. An overcoat of $30 \mathrm{~nm}$ of plasma enhanced chemical vapor deposited silicon nitride was found to inhibit oxidation during annealing. For those multilayers containing thinner carbon layers $(<1 \mathrm{~nm})$, the formation of crystalline $\mathrm{W}_{2} \mathrm{C}$ occurs at annealing temperature as low as $500^{\circ} \mathrm{C}$ and a very small expansion $(<2 \%)$ in the layer $d$ spacing is observed. On the other hand, for all multilayers with carbon layer thickness equal or greater than $2 \mathrm{~nm}$, crystallization occurs at much higher annealing temperatures and the crystalline phases observed were alpha-W and WC. It is also observed that in the latter group the period increases monotonically with increasing annealing temperature, the total expansion is about $10 \%$ and affects both $\mathrm{W}$ and $\mathrm{C}$ layers approximately equally. The expansion stops at the crystallization temperature which occurs at $900^{\circ} \mathrm{C}$ or higher. The expansion is under investigation but may be interpreted as due to the structural ordering processes in the amorphous $\mathrm{W}$ and $\mathrm{C}$ layers.
\end{abstract}

\section{INTRODUCTION}

The interfaces in synthetically produced multilayers ${ }^{1-5}$ provide a novel opportunity to study fundamental interactions between the two layer materials. These interactions strongly depend on the structure of the two layers in contact. ${ }^{6-20}$ For instance, thermally activated atomic diffusion at the interfaces of silicon/germanium amorphous multilayers has been observed without crystallization occurring. ${ }^{19,20}$ Also, the chemical reactivity of a number of metal/ semiconductor interfaces has been demonstrated over the past few years. ${ }^{6-18}$ In many applications such as in synchrotron radiation beam lines and x-ray laser cavities, the thermal stability of the multilayer structure is of considerable importance. Often, the changes induced by elevated temperatures lead to the degradation of the layer structure.

For tungsten/carbon (W/C) multilayers, the results of several annealing studies have been previously reported. ${ }^{6-17}$ Interfacial reactions are observed at annealing temperatures which depend on the structure of the as-prepared multilayer. ${ }^{6-14}$ In addition, it has been observed that the thermal annealings also result in an expansion of the multilayer repeat period. ${ }^{6-12}$ Three different mechanisms have been previously proposed to explain the cause of the expansion: (i) the agglomeration of the $\mathrm{W}$ layers, ${ }^{10,11}$ (ii) the expansion of the carbon layers, ${ }^{12}$ and (iii) the formation of better ordered local atomic rearrangements like those in tungsten carbides after annealing at moderate temperatures. ${ }^{7-9}$

In this report a systematic study on the structure of the asprepared and annealed $\mathrm{W} / \mathrm{C}$ multilayers is presented. The $\mathrm{W}$ and $\mathrm{C}$ layers were both amorphous in the as-prepared structure. Upon annealing interfacial mixing occurs and different crystalline compounds are observed depending on the $\mathrm{W}$ to $\mathrm{C}$ atomic ratio. For samples with the $\mathrm{W}$ layer thicker than the carbon layer, the formation of crystalline $\mathrm{W}_{2} \mathrm{C}$ was observed at an annealing temperature as low as $500^{\circ} \mathrm{C}$. Similar results have been reported before. ${ }^{6}$ For samples with a thicker carbon layer, crystallization takes place at higher annealing temperatures with the formation of alpha-W which then reacts with the carbon to form crystalline WC in a hexagonal phase at the $\mathrm{W} / \mathrm{C}$ interfaces. ${ }^{6,7} \mathrm{We}$ also observed that the crystallization temperature of the $\mathrm{W}$ layer increases with the increase in thickness of the carbon layer. The expansion of the multilayers with a carbon layer of $2 \mathrm{~nm}$ or thicker is approximately $10 \%$ and it is interpreted in terms of structural ordering processes in both the amorphous $\mathrm{W}$ and $\mathrm{C}$ layers.

\section{EXPERIMENTAL}

W/C multilayers with a nominal repeat period varying from 2.5 to $14 \mathrm{~nm}$ were prepared on unheated crystalline (111) silicon substrates by the magnetron sputtering method. The alternating $\mathrm{W} / \mathrm{C}$ layers were deposited by continuously rotating a carousel with the substrates on it over the two sputtering targets. The tungsten and graphite used in the sputtering targets were of a purity better than $99.99 \%$. All samples consisted of 30 layer pairs and a constant $W$ layer thickness of $2 \mathrm{~nm}$ in each pair. The thickness of $C$ layers varied from 0.5 to $12 \mathrm{~nm}$. The $W$ layer was the top layer in the $\mathrm{W} / \mathrm{C}$ multilayer configuration. In this report, the multilayer films are designated by " $\mathrm{C} n$ " where $n$ is the carbon 
thickness in angstroms. All samples were coated with a 30 $\mathrm{nm}$ thick silicon nitride layer to prevent oxidation during the annealings. ${ }^{13}$ The silicon nitride layer was prepared by the plasma enhanced chemical vapor deposition (PECVD) technique at $295^{\circ} \mathrm{C}$ using a gas mixture of $\mathrm{SiH}_{4}, \mathrm{NH}_{3}$, and $\mathrm{He}$ at a pressure of 0.4 Torr. The $\mathrm{W} / \mathrm{C}$ multilayers were subjected to isochronal anneals. That is, they were heated in a quartz tube oven for one hour at a predetermined temperature, characterized by Raman scattering (RS), x-ray diffraction (XRD), and Auger electron spectroscopy (AES) and then returned to the oven for another anneal at a temperature 50 or $100^{\circ} \mathrm{C}$ higher.

The room temperature Raman measurements were recorded in the back scattering geometry using the $488 \mathrm{~nm}$ line from an argon ion laser focused onto the sample using a cylindrical lens. For all measurements the output laser power was $300 \mathrm{~mW}$ and the slits of the double monochrometer were set to achieve a resolution of about $5 \mathrm{~cm}^{-1}$. A small piece was cut from the main sample, the overcoat silicon nitride layer was removed using a low energy $(1.5 \mathrm{keV})$ argon beam and then the Raman spectrum was recorded from that area. The same procedure was followed for each annealing temperature.

AES analysis was carried out in a PHI 550 surface analysis system having base pressure of $<10^{-10}$ Torr. A differentially pumped argon ion gun was used to bombard the sample surface at $30^{\circ}$ from the surface normal to remove the silicon nitride overcoating and, in some samples, the oxygen contaminated layer near the top region of the multilayer films after each annealing.

The layer and atomic structures of the $\mathrm{W} / \mathrm{C}$ multilayer films were determined by XRD measurements. The XRD traces were recorded using a Philips $\Theta-2 \Theta$ diffractometer with monochromatized $\mathrm{Cu} K \alpha$ radiation. The input power of the $\mathrm{x}$-ray source was $800 \mathrm{~W}, 40 \mathrm{keV}$, and $20 \mathrm{~mA}$. High angle XRD trace $\left(2 \Theta>10^{\circ}\right)$ was recorded with the collimations of $1^{\circ}$ divergent and $0.2 \mathrm{~mm}$ detector slits. Collimation widths of $1 / 30^{\circ}$ and $1 / 4^{\circ}$ for divergent and receiving slits were respectively used for the low angle XRD measurements $\left(2 \Theta<10^{\circ}\right)$. A five order logarithmic scale was used to record all XRD traces.

\section{RESULTS}

Figure 1 shows the first order Raman spectra from the asprepared $\mathrm{W} / \mathrm{C}$ multilayers. The nominal carbon layer thickness is indicated at the right-hand side of each curve. The Raman intensity in the vertical axis was recorded using the same scale. All Raman spectra consist of a main feature centered at about $1500 \mathrm{~cm}^{-1}$ and weaker signals at lower frequencies. It is observed that in the recorded frequency range, the Raman intensity increases monotonically with the increase in thickness of the carbon layers. Spectra similar to these have been previously related to an amorphous carbon structure $^{21}$ in which carbon atoms mainly have the threefold, $s p^{2}$, coordination. The high and low frequency features, respectively, originate from the inelastic scattering of the incident photons by optical and acoustic phonons in the disordered graphitic structure. Many authors have suggested the decomposition into two components of the main feature

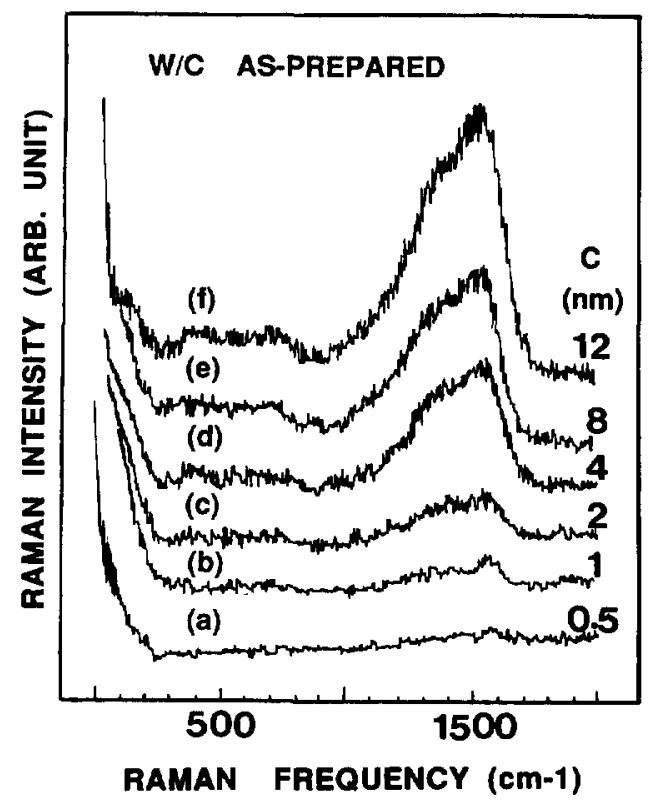

FIG. 1. Raman spectra of the as-prepared $\mathrm{W} / \mathrm{C}$ multilayer films. The $\mathrm{W}$ layer thickness was $2 \mathrm{~nm}$. The $\mathrm{C}$ layer thickness was (a) 0.5 , (b) 1 , (c) 2 , (d) 4, (e) 8 , and (f) $12 \mathrm{~nm}$.

in the spectrum of amorphous carbon: one component is related to the graphite $E_{2 g}$ mode at $\sim 1580 \mathrm{~cm}^{-1}$ and the other, which is induced by the disorder, at $\sim 1380 \mathrm{~cm}^{-1}{ }^{22}$ This is true for microcrystalline or polycrystalline graphite, where the two lines are well resolved, however, there is an indication that in any amorphous $s p^{2}$ coordinated carbon structure the broad main Raman feature may have important contributions from other symmetry points in the phonon dispersion curves with high density of states. ${ }^{23}$ Due to the low Raman cross section of metallic layers no signal related to the $\mathrm{W}$ layers is observed.

Figure 2 exhibits the Raman spectra for the $\mathrm{C} 20$ sample: (a) as-prepared and (b) and (c) after annealing at $600^{\circ} \mathrm{C}$. All data in the figure were recorded under the same experimental conditions. Curve (b) was recorded from a sample which had the silicon nitride overcoating layer during the annealing, but it was removed for the Raman measurement. Spectrum (c) corresponds to a sample without a silicon nitride overcoating layer. Those samples having the silicon nitride protective layer and annealed at $600^{\circ} \mathrm{C}$ revealed minimal changes in the spectrum, the most obvious being the slight increase in the intensity ratio of the 1300 to the 1500 $\mathrm{cm}^{-1}$ peaks. Two noticeable changes occur in the Raman spectrum of the sample without the silicon nitride layer [curve (c) ], one is the appearance of Raman lines at about 250,700 , and $800 \mathrm{~cm}^{-1}$, marked with arrows, and the other is the splitting of the main Raman feature into two lines at about 1380 and $1580 \mathrm{~cm}^{-1}$. Also notice that the intensity of the carbon signal increases by more than one order of magnitude. As reported previously the sharp lines at 700 and 800 $\mathrm{cm}^{-1}$ as well as the features in the range of $200-500 \mathrm{~cm}^{-1}$ are associated with the formation of crystalline $\mathrm{WO}_{3}$ in the triclinic and/or orthorhombic structures. ${ }^{13,24}$ The results of the Auger profiles performed on the as-prepared and an- 


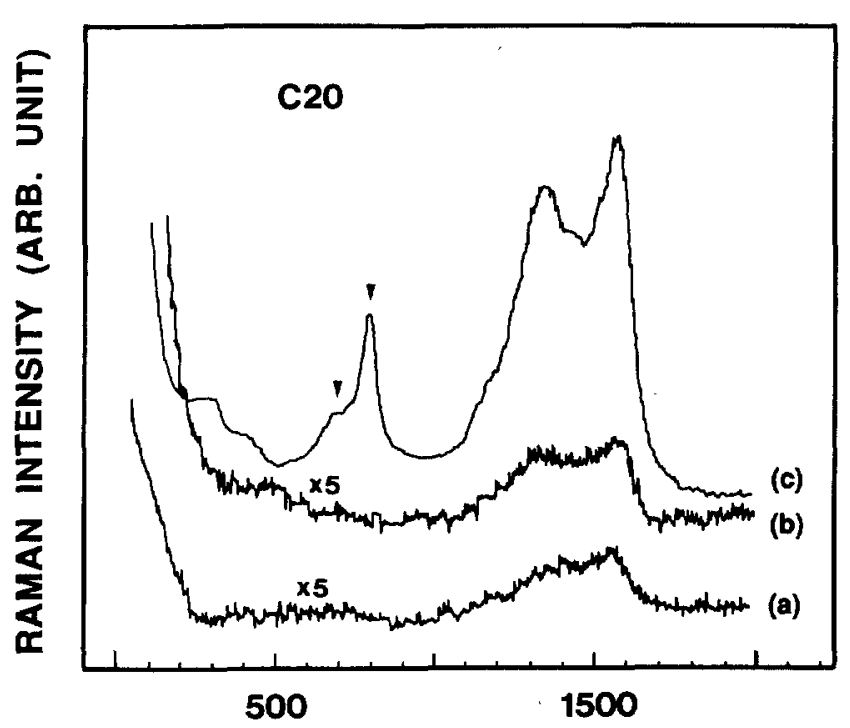

RAMAN FREQUENCY (cm-1)
FIG. 2. Raman spectra of $W(2) / C(2)$ multilayer films: (a) as-prepared; after annealing at $600^{\circ} \mathrm{C}$ for $1 \mathrm{~h} \mathrm{(b)} \mathrm{with} \mathrm{and} \mathrm{(c)} \mathrm{without} \mathrm{silicon} \mathrm{nitride}$ overcoating layer. The arrows indicate the Raman features associated with the formation of crystalline $\mathrm{WO}_{3}$.

nealed samples without the silicon nitride coating indicated that oxygen penetrates into the multilayers to a depth which increases with the increase in annealing temperature but decreases with the increase in carbon layer thickness for a given annealing temperature. ${ }^{13}$ Furthermore, the Auger profile data also indicated the loss of compositional modulation in the oxidized region. ${ }^{13}$

For the particular case shown in Fig. 2(c), the oxygen only penetrates few layer pairs, causing the oxidation of the W layers as well as the increase of the carbon Raman signal which consists of two well defined peaks at 1380 and 1580 $\mathrm{cm}^{-1}$. Based on previous work these changes indicate the crystallization of amorphous carbon to a graphitic structure. ${ }^{21,25}$ The Raman spectrum measured on the same sample after removing the oxygen contaminated region by low energy Ar sputtering revealed a spectrum similar to that shown in Fig. 2(b). This indicates that the crystallization of the amorphous carbon has only occurred in the oxygen reached region, and therefore that oxygen catalyzes the crystallization of the $\mathrm{C}$ layers. ${ }^{13}$ Thicker amorphous carbon films require much higher annealing temperature $\left(>1000^{\circ} \mathrm{C}\right.$ ), under oxygen free conditions, to achieve a degree of crystallinity similar to that displayed in the Raman trace shown in Fig. 2(c) ${ }^{26}$

Figure 3(a) is the XRD trace recorded from the as-prepared C5 sample. A common broad feature centered at $38.5^{\circ}$ is observed in the trace of all as-prepared $\mathrm{W} / \mathrm{C}$ multilayer films. Since the $\mathrm{x}$-ray scattering factor of the $\mathrm{W}$ layer is much larger than that of the $\mathrm{C}$ layer and an amorphous carbon layer would display a broad feature centered at about $23^{\circ}$, this broad feature at $38.5^{\circ}$ is most likely associated with the W layers in the W/C multilayer structure. ${ }^{6.7}$ Disordered or

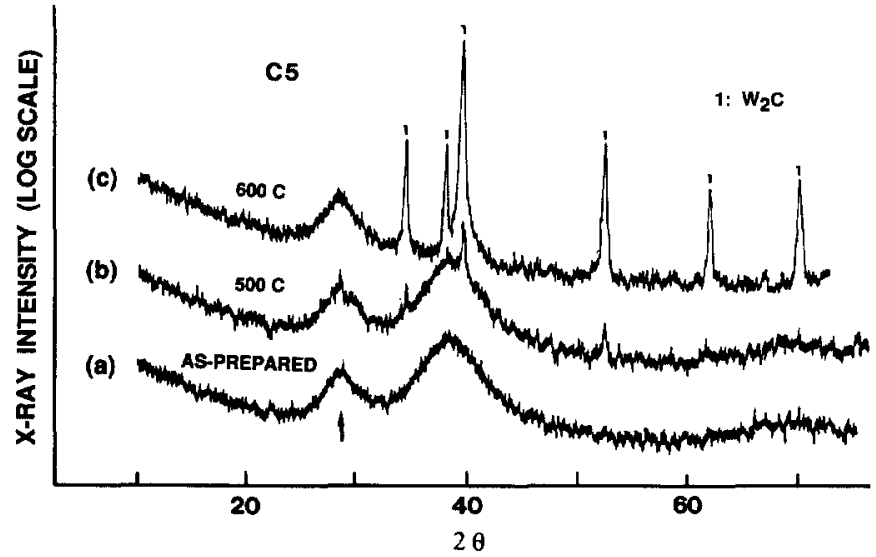

FIG. 3. High angle XRD traces recorded from the W(2)/C(0.5) films: (a) as-prepared; after annealing at (b) 500 and (c) $600^{\circ} \mathrm{C}$ for $1 \mathrm{~h}$ in $\mathrm{Ar}$ flow. The arrow indicates the peak related to the Si substrate. $1: W_{2} C$.

amorphous W layers with thickness up to $4 \mathrm{~nm}$ in W/C multilayers have been reported in the earlier studies. ${ }^{6-9,17}$ From the Raman data presented in Fig. 1 and the $x$-ray data shown in Figs. 3 (a) and 4(a), it is concluded that within the limits of those techniques, both $\mathrm{W}$ and $\mathrm{C}$ layer are in the amorphous state for all the as-prepared films. The peak at $28.5^{\circ}$ marked with an arrow is due to the $\mathrm{Si}(111)$ substrate, its linewidth and low intensity suggests that the $\mathrm{Si}(111)$ orientation is askew from the surface normal. After annealing at $500^{\circ} \mathrm{C}$, the XRD trace of the C5 sample [Fig. 3(b)] reveals several weak and sharp peaks, which are associated with the formation of hexagonal $\alpha-\mathrm{W}_{2} \mathrm{C}$ structure. The broad feature related to the $\mathrm{x}$-ray amorphous $\mathrm{W}$ is still noticeable after heat treatment at $500^{\circ} \mathrm{C}$, but it almost disappeared after the $600{ }^{\circ} \mathrm{C}$ anneal [Fig. 3(c) ], and the intensity of the $\mathrm{W}_{2} \mathrm{C}$ crystalline peaks becomes stronger indicating the increase in the partical size and/or volume fraction of this phase in the film. Annealing at higher temperatures on the C5 sample did not appreciably change the high angle XRD trace.

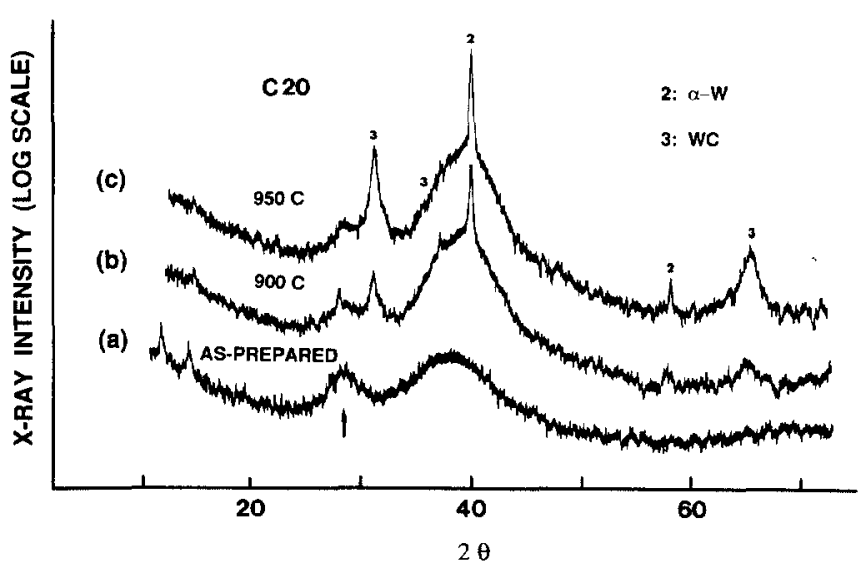

FiG. 4. High angle XRD traces recorded from the W(2)/C(2) films: (a) as-prepared; after annealing at (b) 900 , and (c) $950^{\circ} \mathrm{C}$ for $1 \mathrm{~h}$ in Ar flow. The arrow indicates the peak related to the Si substrate. $2: \alpha-\mathrm{W}$ and $3: \mathrm{WC}$ 
Figures 4(a)-4(c) display the high angle XRD traces of the C20 sample: (a) as-prepared and annealed at (b) 900 and (c) $950^{\circ} \mathrm{C}$ for $1 \mathrm{~h}$. For the as-prepared sample [curve (a) ] the broad feature located at $38.5^{\circ}$ represents the $\mathrm{x}$-ray amorphous nature of the $\mathrm{W}$ layers. The peak marked with an arrow is again related to the Si substrate. The weak and sharp peaks in the range of $10-15^{\circ}$ are related to the layering structure of the sample. The XRD trace was basically unchanged after annealing to temperatures up to $800^{\circ} \mathrm{C}$. In curve (b), several sharp crystalline peaks appear on top of the broad feature after annealing at $900^{\circ} \mathrm{C}$. These peaks are associated with the formation of crystalline $\alpha$-W (body-centered cubic structure) and WC (hexagonal structure). The intensity of these peaks increases after further annealing at $950^{\circ} \mathrm{C}$, as shown in curve (c), indicating the increase in the practical size and/or crystalline volume fraction of these phases in the W/C multilayers. It is also noticed that the WC phase shows a $(00 l)$ preferred orientation. The $\mathrm{x}$-ray amorphous W signal is still present after the $950^{\circ} \mathrm{C}$ annealing with a noticeable increase in its peak intensity, slightly narrowed linewidth and the peak maximum slightly shifted to higher $2 \Theta$ values, approaching the peak position of the $\alpha$-W (110) reflection. ${ }^{27}$

The C40 sample followed a behavior similar to that observed in the $\mathrm{C} 20$ film with the formation of crystalline $\alpha-\mathrm{W}$ and WC after $900{ }^{\circ} \mathrm{C}$ annealing, however, for the $\mathrm{C} 80$ and $\mathrm{C} 120$ samples the initial crystallization in $\alpha$-W and $\mathrm{WC}$ did not occur until after annealing at $950^{\circ} \mathrm{C}$. The XRD trace obtained from the $\mathrm{C} 80$ and $\mathrm{C} 120$ samples after $950^{\circ} \mathrm{C}$ annealing are qualitatively similar to that of curve (b) in Fig. 4.

The Raman spectra were measured on all samples after annealing at $500,600,700,800,900$, and $950^{\circ} \mathrm{C}$ for $1 \mathrm{~h}$. Similar changes in the spectra were observed in all samples. To illustrate the changes, Fig. 5 shows the spectra for the C120 sample before (a) and after annealing at (b) 500, (c) 700 , and (d) and (e) $950^{\circ} \mathrm{C}$. A gradual increase in the Raman signal is observed in the region of $1300-1500 \mathrm{~cm}^{-1}$ for increasing annealing temperature. At $950^{\circ} \mathrm{C}$ the Raman spectrum shows two well defined lines with about the same intensity [curve $5(d)$ ], indicating some crystallization of the amorphous carbon. The result of the Auger profiles measured on the samples after each annealing step indicated that a small amount of oxygen had diffused through the overcoated silicon nitride layer and oxidized the very top W/C layer pair only after annealing at $950{ }^{\circ} \mathrm{C}^{13}$ Curve 5(e) is the Raman spectrum recorded from the same $950^{\circ} \mathrm{C}$ annealed sample but after Ar sputtering to remove the oxygen contaminated region, which in this case was only the first layer pair. It can be seen that this spectrum is very similar to that of curve (a) taken from the as-prepared C120 film. Thus, the carbon Raman signal in curve (d) is the superposition of two components: one obtained from the microcrystalline graphite particles formed in the oxygen contaminated first layer pair region and the other from the amorphous layers beneath. It is then inferred that no drastic changes have occurred in the structure of carbon beyond the first carbon layer.

Figures 6(a)-6(d) display the low angle XRD traces for the $\mathrm{C} 120$ film as-prepared and annealed at various tempera-

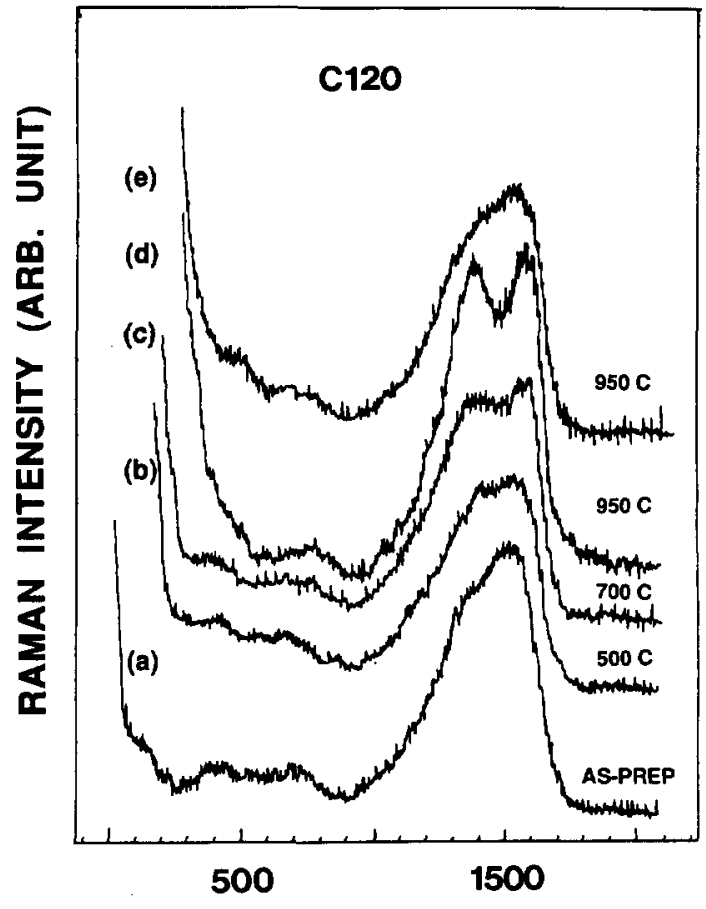

RAMAN FREQUENCY (cm-1)

FIG. 5. Raman spectra of W(2)/C(12) multilayer films: (a) as-prepared; after annealing (b) 500 , (c) 700 , and (d) $950^{\circ} \mathrm{C}$ for $1 \mathrm{~h}$ in Ar flow; (e) same as (d) after Ar sputtering to remove the oxygen contaminated top layer pair.

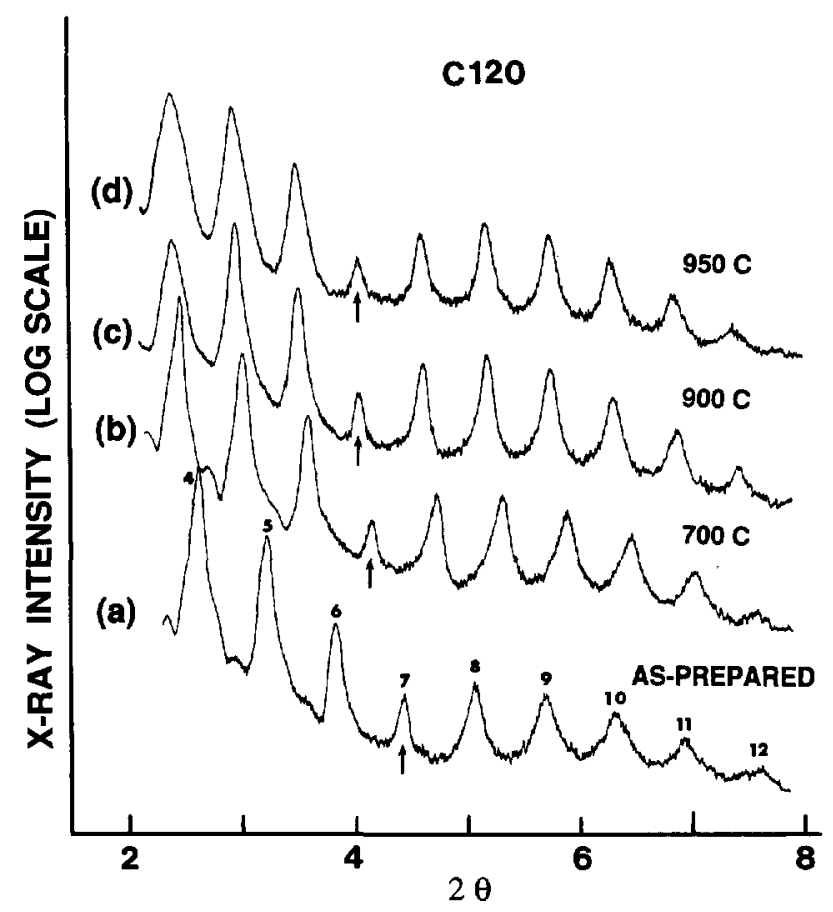

FIG. 6. Low angle XRD traces of $W(2) / C(12)$ films: (a) as-prepared; after annealing at (b) 700, (c) 900 , and (d) $950^{\circ} \mathrm{C}$ for $1 \mathrm{~h}$ in Ar flow. Numericals on top of the peaks represent the orders of the low angle reflections. The intensity of the 7 th order low angle peak, indicated by the arrow, is suppressed. 
tures. In Fig. 6(a), the detection of the sharp low angle peaks up to the 12 th order indicates a good layered structure in the as-prepared film. The number on top of each peak represents the order of the low angle reflection. Due to the fact that for this particular multilayer, the thickness of the carbon layer is six times that of the $W$ layer, the intensity of the 7 th order peak (marked by an arrow) is suppressed, as a result of the destructive interference for this diffraction order. The layer pair spacing determined from the averaged $d$ spacing of the high order low angle reflections was $13.91 \pm 0.02 \mathrm{~nm}$ which is very close to the attempted value of $14 \mathrm{~nm}$. Annealing at temperatures up to $900^{\circ} \mathrm{C}$ slightly sharpened the low angle peaks and shifted them to the lower $2 \Theta$ values,corresponding to larger $d$ spacings. After the $950^{\circ} \mathrm{C}$ anneal, the low angle XRD trace reveals the same number of low angle reflections as that obtained in the as-prepared sample. Furthermore, the 7th order peak remains relatively suppressed with anneals at higher temperatures, as shown in curves $6\left(\right.$ b) -6 (d). Annealing at $950^{\circ} \mathrm{C}$ slightly broaden the linewidth of the lower order low angle peaks, see Fig. 6(d), suggesting some changes in the multilayer structure which degrade the periodicity.

Figure 7 shows the layer pair period as a function of annealing temperature for all multilayers. In the case of C5 and C10 multilayers, the layer pair periods slightly increase with the first anneal, which was at $500^{\circ} \mathrm{C}$, and then decrease when the annealing temperature exceeded $500^{\circ} \mathrm{C}$. This re-

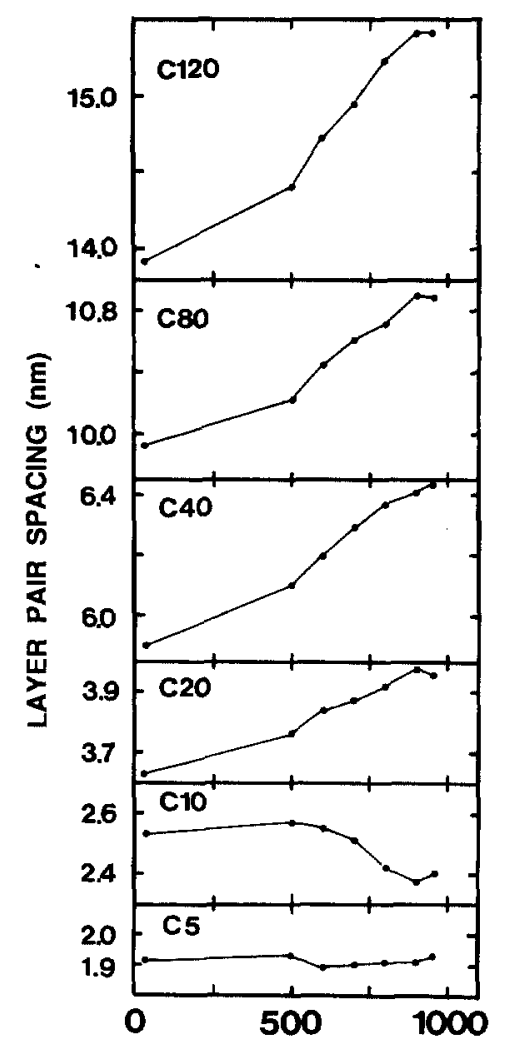

ANNEALING TEMPERATURE $\left({ }^{\circ} \mathrm{C}\right)$

FIG. 7. The layer pair period of each $\mathrm{W} / \mathrm{C}$ multilayer films as a function of the annealing temperature. verse behavior coincides with the formation of crystalline $\mathrm{W}_{2} \mathrm{C}$. For those multilayers containing thicker carbon layers $(\geqslant 2 \mathrm{~nm})$ the expansion of the layer pair periods continues with increasing anneal temperature except for the highest temperature at which a slight contraction is observed when the crystallization of the $W$ layer occurs.

All multilayers with carbon layers greater than or equal to $2 \mathrm{~nm}$ expand at essentially the same extent with increasing annealing temperature, and all appear to have the same onset for expansion between $300-400^{\circ} \mathrm{C}$. The relative rate of increase is approximately uniform and is approximately the same for all multilayers up to the point that crystallization takes place. The rate is about $1.4 \% / 100^{\circ} \mathrm{C}$ for the $\mathrm{C} 20$ and $\mathrm{C} 40$ films and $1.7 \% / 100^{\circ} \mathrm{C}$ for the $\mathrm{C} 80$ and $\mathrm{C} 120$ films. The total expansion of the layers is constant and remarkably large, $10 \%-11 \%$, for all the films containing more than $1 \mathrm{~nm}$ of carbon per period, see Fig. 8.

\section{DISCUSSION}

As previously reported, the annealing behavior of $\mathrm{W} / \mathrm{C}$ multilayers depends largely on the structure of the as-deposited films. Particularly, it has been pointed out that the annealing temperature at which the chemical reaction between the $W$ and $C$ layers occurs depends on the thickness of the $W$ layer. ${ }^{6-9,13}$ For the present study the as-prepared $\mathrm{W}$ layer thickness was $2 \mathrm{~nm}$ and it was found to have an amorphous structure. Upon annealing, the formation of crystalline phases depend on the $\mathrm{W} / \mathrm{C}$ atomic ratio. For the $\mathrm{C} 5$ sample having a W:C atomic ratio of $2: 1$ and the very thin carbon layers, a $W_{2} C$ crystalline phase is formed at annealing temperature as low as $500^{\circ} \mathrm{C} .{ }^{6}$ Annealing at temperatures up to $950^{\circ} \mathrm{C}$ do not change the $\mathrm{W}_{2} \mathrm{C}$ crystalline phase. For samples having the $\mathrm{W} / \mathrm{C}$ ratio less than 2 , the nucleation occurs at much higher annealing temperatures with the formation of two different crystalline phases, $\alpha$-W and WC. $6,7,9$

The XRD results suggest that in multilayers with thicker carbon layers the mixing only occurs at an annealing temperature for which the $W$ layer partially crystallizes and that the formation of the crystalline WC phase proceeds immedi-

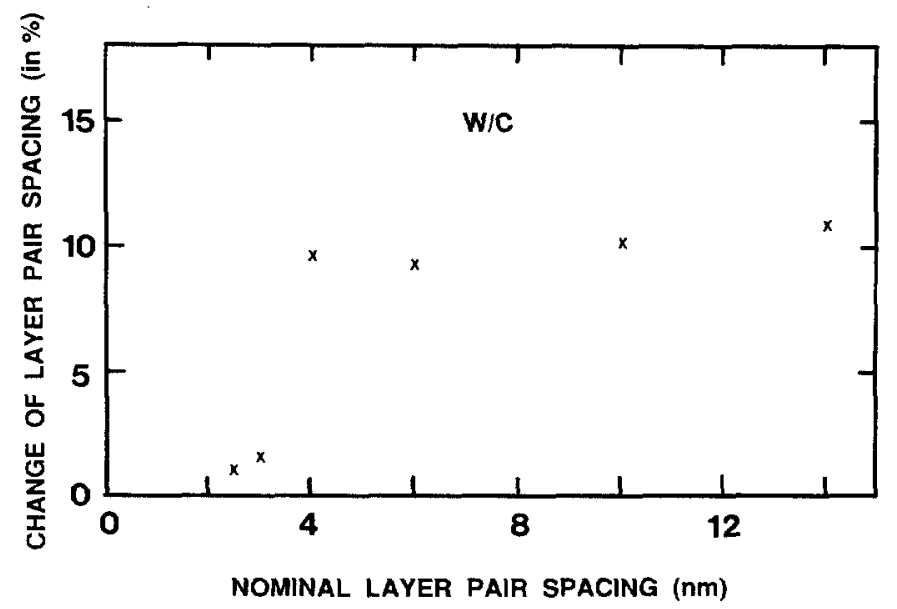

FIG. 8. The total expansion (in \%) of layer pair period for all the $\mathrm{W} / \mathrm{C}$ multilayer films. 
ately. It is also found that the crystallization temperature of the $\mathrm{W}$ layer along with the formation of WC depends on the thickness of the Clayers. Thus, this transformation occurs at annealing temperatures of $950^{\circ} \mathrm{C}$ in the $\mathrm{C} 80$ and $\mathrm{C} 120$ samples and occurs at $900^{\circ} \mathrm{C}$ in the $\mathrm{C} 20$ and $\mathrm{C} 40$ samples. The retardation in the crystallization of the $W$ layer is similar to the behavior observed in the $a-\mathrm{Ge}: \mathrm{H} / a-\mathrm{Si}: \mathrm{N}: \mathrm{H}$ multilayers where the crystallization of the $a-\mathrm{Ge}: \mathrm{H}$ layers depends on the thickness of both layers. ${ }^{28}$

The expansion of the multilayer during annealing is especially noteworthy. For all multilayers with a carbon layer thickness greater than $2 \mathrm{~nm}$, there is an approximately $10 \%$ expansion in the repeat period. Two explanations have been previously proposed for this rather surprising effect, expansion of the carbon layers, ${ }^{12}$ or agglomeration or roughening of the $\mathrm{W}$ layers. ${ }^{10,11}$ Volume changes of more than $10 \%$ are known in the case of the annealing of amorphous semiconductors. However, these volume changes are usually decreases rather than increases, and volume changes for metals such as tungsten are typically smaller than for semiconductors. It is noted that if the increase in lattice spacing is due to such an expansion, the amorphous state would have to be more dense than the crystalline state. This is possible since the packing density of tungsten atoms in its natural bodycentered-cubic (bcc) structure with eight nearest neighbors may be lower than in the amorphous state which could be in a face-centered-cubic ( $\mathrm{fcc}$ ) close-packed coordination with between eleven and twelve nearest neighbors. Based on similarities with osmium and iridium, which are the elements with an atomic number two and three higher than tungsten and crystallize in the hexagonal-close-packed (hcp) and fcc close-packed structures, this increase could be $12 \%$. However, from the relative constant increase with temperature after the onset and the absence of any crystalline peaks until higher temperatures the volume expansion cannot be attributed to amorphous to crystalline conversion per se, although the expansion conceivably might be due to the reorganization of an amorphous state preceding crystallization. The reorganization of $a-C$ could also cause it to expand. The atomic density of $s p^{3}$ carbon is higher than that of $s p^{2}$ bonded carbon as can be seen by contrasting the densities of diamond and graphite, 3.51 and $2.25 \mathrm{~g} / \mathrm{cm}^{3}$, respectively. If a portion of the deposited carbon is $s p^{3}$ which reverts to $s p^{2}$ upon annealing, the volume of the carbon layer could increase even more than is conceivable for tungsten. From the Raman measurements on annealed samples, no changes in bonding structure are observed. This is possibly due to the much lower Raman cross section of carbon-carbon bonds with the $s p^{3}$ coordination. $^{21}$

According to the low angle XRD data presented in Fig. 6, the 7 th order peak which is suppressed in the as-prepared state of the $\mathrm{C} 120 \mathrm{film}$ remains relatively suppressed after annealing at higher temperatures, up to $950^{\circ} \mathrm{C}$. Similar observations are also found in the $\mathrm{C} 80, \mathrm{C} 40$, and $\mathrm{C} 20$ samples where the low angle peaks corresponding to the 5th and 10th, 3rd and 6th, and 2 nd and 4th orders, respectively, are suppressed in the as-prepared and annealed states. This is strong evidence that the multilayer expansion cannot be solely attributed to the expansion of the $C$ layers but rather both the carbon and the tungsten layers expand at approximately the same rate. The relative intensity of the suppressed peak would otherwise change dramatically upon annealing.

We have ruled out the mechanism of $W$ agglomeration for layer expansion, ${ }^{10,11}$ that is, the transport laterally of atoms within a layer of tungsten or carbon from one part of the film to another to increase the thickness in one region at the expense of another. This model avoids problems with molar volume expansion and does not account for how the low angle XRD reflectivity is maintained (see Fig. 6).

Another mechanism that has been proposed to explain the layer expansion is the formation of $\mathrm{W}-\mathrm{C}$ compounds upon annealing. ${ }^{7-9}$ This study shows that in samples having $\mathrm{C}$ layer thickness $\geqslant 2 \mathrm{~nm}$, the layer pair periods increase monotonically with increasing annealing temperature up to 900 or $950^{\circ} \mathrm{C}$. The expansion stops at temperature when crystallization takes place with the formation of $\alpha-W$ which then reacts with the carbon to form crystalline $\mathrm{WC}$ at the $\mathrm{W} / \mathrm{C}$ interfaces. ${ }^{27}$ Thus, premixing during earlier annealing temperatures is also unlikely as the mechanism responsible for the expansion.

\section{CONCLUSIONS}

Amorphous $\mathrm{W} / \mathrm{C}$ multilayers have been annealed up to $950^{\circ} \mathrm{C}$ under Ar flow conditions. An overcoating layer of 30 $\mathrm{nm}$ silicon nitride has demonstrated to be sufficient to prevent surface oxidations in the multilayers at annealing temperature up to $950^{\circ} \mathrm{C}$. The crystalline phase of $W_{2} \mathrm{C}$ is present in those multilayers having thinner carbon layers $(<1$ $\mathrm{nm}$ ) at an annealing temperature as low as $500^{\circ} \mathrm{C}$. On the other hand, the crystalline phases of $\alpha-W$ and WC appear on all multilayers with carbon layer thickness greater than or equal to $2 \mathrm{~nm}$ at much higher annealing temperatures $\left(>900^{\circ} \mathrm{C}\right.$ ). In the latter group, it is observed that the layer period increases monotonically with the increase in the annealing temperature, the total expansion of both the $W$ and C layers is about $10 \%$ and stops at a crystallization temperature of $900^{\circ} \mathrm{C}$ or higher. It is also inferred that both the $\mathrm{W}$ and $C$ layers expand at approximately the same rate. The results suggest that the expansion is associated with structural ordering processes in the amorphous $\mathrm{W}$ and $\mathrm{C}$ layers. Furthermore, no significant interlayer diffusion is inferred in the multilayers until the crystallization takes place at rather high temperatures $\left(>900^{\circ} \mathrm{C}\right)$.

\section{ACKNOWLEDGMENT}

We like to thank the constant encouragement of S. R. Oyshinsky of ECD.

\footnotetext{
a) On leave from Depto. de Fisica, CINVESTAV-IPN, Ap. Postal 14-740, Mexico.

'A. M. Kadin and J. E. Keem, Scr. Metall. 20, 443 (1986).

${ }^{2}$ J. L. Wood, N. J. Grupido, K. L. Hart, S. A. Flessa, A. M. Kadin, J. E. Keem, and D. H. Ferris, in Application of Thin Film Multilayered Structures to Figured X-Ray Optics, edited by G. F. Marshall [SPIE Proc. 563, $238(1985)]$.

${ }^{3}$ J. H. Underwood and T. W. Barbee, Jr., Appl. Opt. 20, 3027 (1981).
} 
${ }^{4}$ T. R. Barbee, Jr., in Low Energy X-Ray Diagnostics-1981, edited by D. T. Attwood and B. L. Henke [AIP Conf. Proc. 75, 131 (1981)].

${ }^{5}$ E. Spiller, in Ref. 4, p. 124.

${ }^{6}$ Y. Takagi, S. A. Flessa, K. L. Hart, D. A. Pawlik, A. M. Kadin, J. L. Wood, J. E.Keem and J. E. Tyler, in Ref. 2, p. 66.

${ }^{7}$ Y. Takagi, D. A. Pawlik, A. M Kadin, S. A. Flessa, K. L.Hart, J. E. Keem, and J. E. Tyler, Mater. Res. Soc. Proc. 56, 441 (1986).

${ }^{8}$ J. B. Kortright and J. D. Denlinger, Mater. Res. Soc. Proc. 103, 95 (1988).

${ }^{9}$ T. D. Nguyen, R. Gronsky, and J. B. Kortright, Mater. Res. Soc. Proc. 139, 357 (1989); 187, 95 (1990).

${ }^{10}$ E. Ziegler, Y. Lepetre, I. K. Schuller, and E. Spiller, Appl. Phys.Lett. 48, 1354 (1986).

${ }^{11}$ Y. Lepetre, E. Ziegler, and I. K. Schuller, J. Appl. Phys. 60, 2301 (1986).

${ }^{12}$ Xiaoming Jiang, Dingchang Xian, and Ziqin Wu, Appl. Phys. Lett. 57, 2549 (1990).

${ }^{13}$ B. S. Chao, J. Gonzalez-Hernandez, D. A. Pawlik, Qi Wang, and D. D. Allred, Mater. Res.Soc. Extended Abstract EA-21, 185 (1990).

${ }^{14}$ C.-H. Chang, M. B. Stearns, and D. Smith, Mater. Res. Soc. Proc. 139, 339 (1989).

${ }^{15}$ A. F. Jankowski, L. R. Schrawyer, M. A. Wall, W. W. Craig, R. I. Morales, and D. M. Makowiecki, J. Vac. Sci. Technol. A 7, 2914 (1989).

${ }^{16}$ A. K. Petford-Long, M. B. Stearns, C.-H. Chang, S. R. Nutt, D. G.
Stearns, N. M. Ceglio, and A. M. Hawryluk, J. Appl.Phys. 61, 1422 (1987).

${ }^{17}$ P. Ruterana, J.-P. Chevalier, and P. Houdy, J. Appl. Phys. 65, 3907 (1989).

${ }^{18}$ D. G. Stearns, M. B. Stearns, Y. Cheng, J. H. Stith and N. M. Ceglio, J. Appl. Phys. 67, 2415 (1990).

${ }^{19}$ S. M. Prokes and F. Spaepen, Appl. Phys. Lett. 47, 234 (1985).

${ }^{20}$ D. D. Allred, J. Gonzalez-Hernandez, O. V. Nguyen, D. Martin, and D A. Pawlik, J. Mater. Res. 1, 468 (1986).

${ }^{21}$ N. Wada, P. J. Gaczi, and S. A. Solin, J. Non-Cryst. Solids 35, 543 (1980).

${ }^{22}$ F. Tuinstra and J. L. Koeing, J. Chem. Phys. 53, 1126 (1970).

${ }^{23}$ Qi Wang, D. D. Allred, and J. Gonzalez-Hernandez (unpublished).

${ }^{24}$ R. E. Benner, J. R. Mitchell, and R. W. Grow, IEEE Trans. Elec. Devices 34, 1842 (1987).

${ }^{25}$ J. Gonzalez-Hernandez, B. S. Chao, and D. A. Pawlik, J. Vac. Sci. Technol. A 7, 2332 (1989).

${ }^{26}$ R. O. Dillon and K. A. Woollam, Phys. Rev. B 29, 3482 (1984).

${ }^{27}$ B. S. Chao, J. Gonzalez-Hernandez, D. A. Pawlik, S. R. Ovshinsky, J. Scholhamer, J.L. Wood, and K. Parker, in Multilayer Optics for Advanced X-Ray Applications, edited by N.M. Ceglio [SPIE Proc. (in press)].

${ }^{28}$ J. Gonzalez-Hernandez and D. D. Allred (unpublished). 